\title{
The Need for Ecotourism at Our Third Pole and Their Sustainable Development and Policy Responses
}

\author{
Yi Wang', Chenhaojia Liu ${ }^{2}$, Chenyu Wang, * \\ ${ }^{1}$ Brandeis University, Waltham, MA 02453, USA \\ ${ }^{2}$ University of Manchester, Manchester M13 9PL, UK \\ 3New York University, New York, NY 10003, USA \\ *Corresponding author: Chenyu Wang (Email: cw2922@nyu.edu)
}

\begin{abstract}
The term ecotourism was originally proposed to rethink culture, education, and tourism, and has developed into a foundational concept for international natural ecological sustainability. This paper uses a combination of desktop research and literature research to explore the necessity, feasibility, and sustainability of ecotourism in the Third Pole, specifically analyzing the current situation, strengths and weaknesses, and four potential problems of ecotourism in the Tibetan Plateau, and making recommendations, including, but not limited to, the introduction of encouraging and restrictive policies for local tourism practitioners and people from the tourism industry.
\end{abstract}

Keywords: Ecotourism industry, Sustainable environmental protection, Tibetan Plateau, Third pole ecotourism policy support.

\section{Introduction}

Ecotourism, as a model and practice of tourism with new social values, was defined as "a traditional form of tourism" at the International Conference on the Environment in 1986, and in 1993, the International Ecotourism Society defined ecotourism as a tourism activity with the dual responsibility of protecting nature and preserving the livelihoods of local people. In 1995, China defined ecotourism as a tourism activity to enjoy, understand, and protect natural and cultural heritage through ecological science education and scientific popularization.

The Tibetan Plateau has a beautiful natural environment, unique resources, regional typicality and great conservation value. This third pole region is less affected by human activities and is an important place in China for maintaining the balance of natural ecosystems, protecting the ecological environment and biodiversity, developing ecotourism, conducting scientific research and environmental education [1].

This paper uses the SWOT strategic analysis model as the basic method, i.e., analyzes the favorable internal advantages and external opportunities in the region and the unfavorable internal disadvantages and external threats to regional development, explores the current situation and existing problems of ecotourism in the third pole of the Tibetan Plateau, and analyzes feasible countermeasures from the perspectives of internal and external, encouragement and support, and restriction and protection.

\section{Current Status of Ecotourism Development on the Tibetan Plateau}

\subsection{Analysis of the Advantages of Developing Ecotourism on the Tibetan Plateau}

The Qinghai-Tibet Plateau is high and has a special geographical location. It is rich in wildlife resources, water resources, and mineral resources. The magnificent QinghaiTibet Plateau, known as the "Roof of the World" and the "Third Pole", contains the code of the earth's ecological environment and many natural mysteries to be explored. From the perspective of natural resources, the relevant data show that the autonomous region has 29 excellent tourism resources, and 160 excellent tourism resources in the region [2]. From the perspective of tourism resources, the natural landscape along the Qinghai-Tibet Railway is a unique beauty in the world, including the Coco Cili Nature Reserve and Qiangtang Nature Reserve. In the vast wilderness, tourists can see herds of Tibetan antelopes, Tibetan wild asses, yellow sheep and other rare wild animals, as well as the source landscapes of the Yangtze and Yellow rivers.

\subsection{Analysis of the Disadvantages of Developing Ecotourism on the Tibetan Plateau}

Tourism has largely become a pillar of industry and an economic source in some parts of the country. The ecotourism industry in the Tibetan plateau still faces many development shortcomings that need to be improved.

\subsubsection{Too few and Concentrated Tourist Seasons}

The average altitude of over 4,000 meters makes many tourists suffer from plateau reactions due to the high temperature and lack of oxygen. Moreover, Extreme weather conditions such as high winds and hail caused by seasonal changes make only the months of April to May and September to October suitable for sightseeing. In this case, too much concentration of suitable travel periods can lead to instability in the travel industry. At the same time, the influx of tourists during this period of time (when the population exceeds the environmental capacity for a short period of time) affects plants and animals in the growing and breeding period of the third pole.

\subsubsection{Difficult to Develop Tourism Resources, Backward}

Market Management and Insufficient Funds

As an economically underdeveloped region, the QinghaiTibet Plateau has limited funding for tourism development, mainly from national financial allocations, and there are difficulties in introducing foreign investment to develop tourism. There are some problems such as the chaos of the Qinghai-Tibet Plateau tourism market, the low management 
level of relevant departments and the poor quality foundation of employees. Due to the late start of development, the industry regulations are not perfect, and the service quality control has not yet formed an effective supervision and management mechanism. The tourism industry operators aim to make money, which easily causes damage to the environment and reputation.

\subsubsection{Natural Ecological Fragility}

As a kind of ecological barrier, the Tibetan plateau contains many ecologically sensitive and fragile areas. Once damaged, it is very difficult to recover. A large number of tourists entering the third pole region makes the plateau vulnerable to various kinds of pollution. The self-healing process of the ecological environment is damaged, which not only affects the image of the scenic area but also greatly reduces the tourism experience, value and prospects.

\subsection{External Opportunities}

The 2017 national park system reform effort and the launch of the General Plan for the Establishment of the National Park System [1], the release of the 2021 White Paper on the Peaceful Liberation and Prosperous Development of Tibet, and other national project instruments will drive the living standards of the people of the Tibetan Plateau region and bring a significant economic boost and development momentum to the region [3] .

\subsection{Potential Difficulties and Challenges of Tourism Activities in the Tibetan Plateau}

Domestic ecotourism development is still in its infancy, and the third pole ecotourism lacks rule of law and standardized management. In addition, ecotourism on the Tibetan Plateau still needs more mature ecotourists and practitioners to participate in it and adhere to the strategy of both development and protection, which is the only way to make ecotourism industry in the region develop and grow rapidly and healthily.

\section{The Need for Ecotourism on the Tibetan Plateau and the Direction of Its Development}

Through the above analysis of the advantages and disadvantages, difficulties and opportunities of local ecotourism resources, it can be seen that ecotourism is a need for the construction of civilization in the Tibetan Plateau region and an inevitable choice to achieve sustainable economic development in the Tibetan Plateau region. The tertiary industry such as tourism in the Tibetan Plateau will bring a certain inflow of government funds, the proportion of income such as traditional livestock population will be adjusted, and the problem of unstable industrial pillars will be effectively alleviated. In turn, when it comes to ecological sustainability, a healthy ecological environment not only relies on nature's perennial self-iteration but also relies on the strong support of a large number of human and material resources. The environmental protection and future development of the Tibetan Plateau region require the active commitment and courage of the people and the government. Nowadays, population loss and lack of financial resources make it difficult to strengthen the mutual sustainability between people and nature.
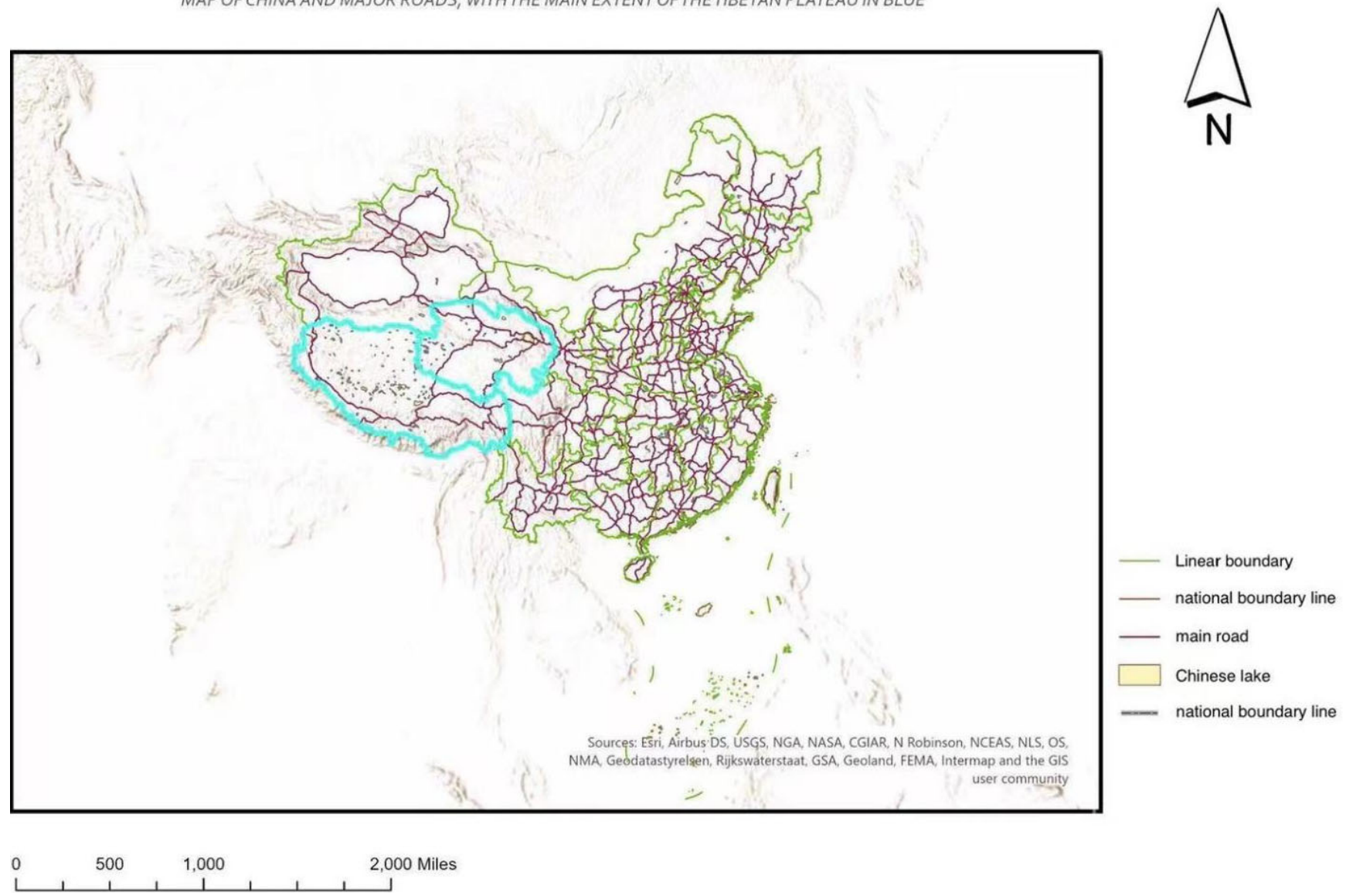

Figure 1. Map of China and major roads, with the main extent of the Tibetan Plateau in blue 
The ideal development direction is to continue to develop the tourism industry to attract tourists while increasing investment in environmental protection through modern and legalized policy restrictions and incentives, so that when the tourism industry and the ecological environment reach a point of balance, a healthy and mutually sustainable closed loop will be formed and economic growth will lead to changes in the industrial pillars and increased employment opportunities, thus attracting young people back to their hometowns and enhancing ecological conservation resources. Reaching a lasting pair of environmental protection purposes.

\subsection{Existing Issues Related to Ecotourism Development}

Although ecotourism has a positive effect on the maintenance of natural ecology and the enhancement of regional economic development, there are at the same time some hidden dangers, and the problems it reveals should not be underestimated.

(1) Excessive numbers of tourists will hurt the livelihoods of residents and the tourism experience of other travelers, and the region will not be able to cope with the ecological impact of excessive visitor numbers.

(2) The amount of household waste brought or caused by tourists is so large that it cannot be disposed of properly under the influence of local traffic conditions and the environment, thus causing all kinds of environmental pollution. Another part of tourists causes irreversible damage to the environment because they do not understand the local ecological situation or are under deliberate emotions.

(3) The Third Pole tourism area is located on the Tibetan plateau, where is high, cold, lack of oxygen and complex terrain makes it difficult to build roads. Tourists are difficult to take an active interest in projects that require long-distance travel, such as natural ecotourism at the Third Pole.

(4) Some businesses or individuals over-develop and build recreational structures for profit, destroying the local ecological environment. These actions can lead to the destruction of the original local character and can easily change the lifestyle of the local population.

\section{Suggested Countermeasures for Sustainable Ecotourism Development}

\subsection{Restrictive Policies}

On account of the legal system for the management of national parks in China has not yet been fully established, in order to promote the protection of the ecological environment and cultural heritage, China should learn from the advanced experience overseas and formulate laws and regulations for the current situation of national parks in China, to implement the standardization of management [1]. The threat of ecotourism, intuitive or potential, must be controlled by appropriate measures and regulations to minimize the impact on local nature and culture. The implementation of restrictive policies should be carried out in two ways.

In the case of foreign tourists, policies need to be put in place to strictly limit their misconduct. From the last century, as the Sanjiangyuan region became more and more involved with the mainland, new-age industrial products gradually began to pour into the plateau. Unlike the efficient cleaning systems in many of China's provinces, waste pollution is a very serious problem for pastoral areas because of the plateau's unique ecological environment and the relatively lagging nature of its infrastructure. Although in recent years Qinghai province has strongly supported the construction of cleanliness and the "the plastic bag ban" in some areas [4], the influx of foreign tourists and uncontrolled pollution will still cause a great blow to the third pole ecosystem. As a matter of policy, the number of tourists should be limited and the throwing of single-use plastic products by tourists should be strictly prohibited. And in ecotourism viewing areas that are less inhabited by humans, tourists should be banned from bringing in any plastic products to prevent damage to the ecosystem. In addition, tourists should be prohibited from capturing local organisms and bringing exotic animals into protected areas to prevent damage to the local ecological balance. To ensure the effectiveness of the policy, the relevant authorities need to formulate some enforceable rules to impose financial penalties on tourists who violate the rules such as putting them on the local ecological blacklist, so as to restrict or even prohibit them from re-entering the Third Pole in the future in serious cases.

And modest restrictions are also necessary for the locals. In many other protected areas and attractions, local businesses have overdeveloped for profit, building recreational structures and destroying the local ecology. One of the main attractions for tourists in Malaysia's Cameron Highlands, for example, is agritourism. The massive construction of tea plantations and farms has led to the overexploitation of local land, which has directly contributed to landslides and rising temperatures. It is therefore likely that the area's main tourist selling point will be destroyed, and in response, experts have urged the authorities to take action to prevent further damage and to develop a long-term plan to ensure the area is protected [5]. To prevent such problems, the authorities should manage the area upfront and limit ecological damage for profit. Adequate preparations should be made well in advance before the Third Pole is opened to the public. The relevant departments need to plan the traveler routes reasonably and give full consideration to the habitats and activity routes of different organisms to minimize the damage to the habitats and biological activities. While developing tourism resources, the current environmental conditions should be maintained, while focusing on ecological conservation and restoration.

To protect the local environment and maintain ecological balance, the Third Pole must be divided into several different types of areas for different functions, taking into account the policies of other protected areas. For example, Canada's Banff National Park is divided into five different zones, namely absolute protection zones, wilderness areas free from human interference, natural scenic tourist areas, recreational areas and tourist town areas [6], and different rules are set for different zones to regulate human behavior. In the face of domestic ecotourism, the Tibetan Plateau can be divided into core areas, buffer zones, human interference areas, etc. The endangered species and the more fragile ecological balance of the Qinghai-Tibet Plateau will be divided into core areas. As the most important environmental protection area of the Third Pole, it will require the strictest protection measures, and the entry of any human not engaged in scientific research will be strictly prohibited. Outside the core zone, a circle will be divided as a buffer zone. This section of land will be protected as a core area and will be off-limits to all visitors, with only 
scholars conducting research being allowed to enter after permission [7].

The only land that is permitted to be accessed by tourists is that which is divided into areas of human disturbance. Here, businesses and individuals are permitted to build homes, roads, develop industries, produce labor and tourism. This land, being relatively ecologically stable and with little wildlife, is allowed to be actively interfered with by humans. In the author's opinion, the areas where human interference can take place can be divided again into two types: ecotourism areas and residential areas. In the residential areas, tourists can enjoy Tibetan specialties, special souvenirs and a special type of accommodation: the black tent. In the residential areas, the rules are more relaxed: it is allowed to carry and dispose of plastic waste in a designated place, etc. In the tourist areas, however, restrictions are placed on visitors and their luggage so that travelers do not actively or unintentionally discard ecologically polluting items in places that are difficult to clean up, thus affecting the local ecology.

\subsection{Incentive Policies}

One of the highlights of ecotourism is the traditional culture and lifestyle of the region, so developing ecotourism in the Third Pole needs to be based on the existing survival patterns of Tibetans. Local Tibetans, as the group with the deepest understanding and most affection for the Sanjiangyuan region, the indigenous people and communities can benefit from this. By educating local people culturally and spreading ecological conservation knowledge, they can understand the importance of environmental and ecological conservation, which can empower indigenous people with ecological conservation while living their daily lives.

Grassland pastoralism is an important part of Tibetan areas that distinguishes them from the rest of the world, and ecotourism can only be produced or implemented if the original pastoral model is maintained, with Tibetan culture and the lifestyle of the local people as the attraction. These "special" products, which are different from those of the mainland, will be a point of attraction for tourists to explore. On the other hand, products with ethnic characteristics such as felt products, yak products, yak dairy products, black tents, etc. can be implemented to help the ecological economics of the community grow. According to an interview with Dong Zhou Qunpei, secretary-general of the Sanjiangyuan Ecological Protection Association, the local handicraft cooperative earned a total of about 200,000 RMB last year, including costs. He said that the local Tibetans are very much in agreement with such a cultural way of life and hope to make their hometown better and better through their efforts "The handicraft cooperatives are very cohesive, and everyone helps each other." Policy subsidies such as tax breaks and free training in basic skills could therefore be offered to residents who are willing to start commercial activities to promote other industries.

On this basis, the relevant authorities can attract tourists through innovative tourism methods such as the development of trekking eco-tourism, or they can actively engage in regional cooperation to jointly create quality tourism routes, strengthen regional solidarity and jointly cultivate a large tourism market in the west. Local tourism bureaus can choose to cooperate with the transport sector to provide reasonable travel routes to facilitate tourists' access to eco-tourism areas, which can solve the problem of overly long distances to a certain extent. In addition, the relevant departments of the regional tourism bureau could work with scientific researchers to examine a route where rare local species can be observed as a promotional point. Equipping tourists with residents as guides is also good medicine, which can help tourists understand ecological protection and other knowledge in all aspects, as well as get close to the daily life of residents, thus promoting excellent national culture more transparently and cultivating cultural industries in the Tibetan Plateau region. In the era of the Internet+, the local tourism bureau can launch live streaming and other traffic activities in collaboration with the Chamber of Cultural Industries to attract the attention of various groups of people from all over the world at a distance, while eco-tourism publicity and education can be widely carried out online to improve the quality of tourism practitioners and travelers.

With the large population loss in recent years, the local government could introduce policies to encourage out workers and young residents to return to their hometowns to start businesses or work in the reserve. In the construction of ecotourism areas, guides and patrols are needed, and residents are the best choice for various occupations in the areas. The implementation of ecotourism in the third pole will provide a large number of employment opportunities for residents, which will not only attract people who have left their hometowns to return and start their businesses but also allow more young people to choose to stay and build their hometowns, avoiding the aggravation of aging in remote areas.

\section{Rural population loss in Qinghai province in recent years}

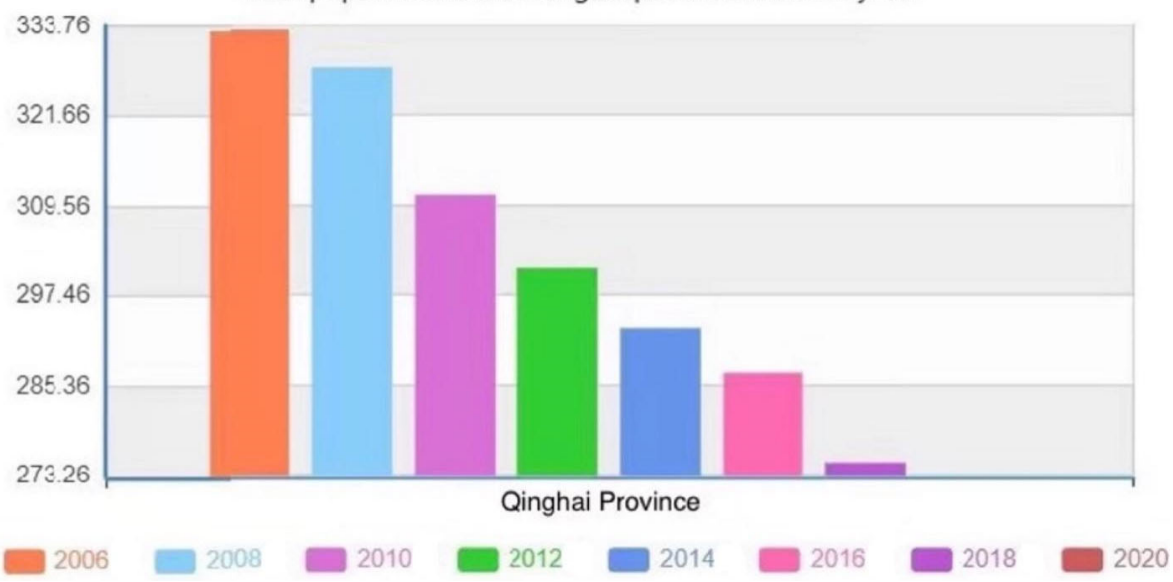

Figure 2. Rural population loss in Qinghai Province in recent years, National Bureau of Statistics (https://data.stats.gov.cn/easyquery.htm? cn=E0103\&zb=A0301\&reg=630000\&sj=2020) 


\section{Prospects for Ecotourism on the Tibetan Plateau}

Nowadays, it is particularly important and urgent to raise awareness of ecotourism and environmental protection, and both governments and practitioners need to prepare well in advance for the development of diversified travel products and special services. Consider the habitats and routes of different organisms, and plan the routes of tourists in a reasonable way to minimize damage to habitats and biological activities. While developing tourism resources, the current environmental conditions should be maintained and ecological conservation and restoration should be emphasized.

The following strategies can be actively and effectively implemented by all parties for a rational and sustainable ecological development of the third pole.

Innovative tours and complete travel itineraries to attract tourists

Introduce an ecotourism zoning law to separate core areas, buffer zones, and areas of human disturbance (tourist areas, residential areas) for management

Develop recommendations for different types of responses to businesses and visitors, including but not limited to incentive and restrictive policies

Increased employment opportunities through ecoadvocates, local cultural guides, handicraft workshops, etc.

Effective long-term education of residents on ecological protection and other issues

The spectacular natural scenery, magical cultural landscape, and unique ethnic culture have made the Tibetan Plateau a paradise for tourists from home and abroad. The QinghaiTibet Plateau is of great significance to the earth's environment and human life, and the third pole ecotourism needs to be based on nature, supplemented by the enhancement of environmental education, with an eye on sustainable tourism management, to achieve the purpose of improving the economy and perfecting ecological construction and protection. Only by effectively implementing countermeasures in the areas of the management system, ecological conservation planning, marketing strategy, resident participation, and the quality of practitioners will the future of the ecotourism industry on the Tibetan Plateau become clear and promising.

\section{References}

[1] J. Hu, "National park system general plan issued 'national park' is a park for whom?," CPPCC, 2017. https://web.archive.org/web/20170930222513/http://www.chi na.com.cn/cppcc/2017-09/28/content 41659459.htm (accessed Nov. 19, 2021).

[2] Beijing Tsinghua Institute of Urban Planning and Design, Survey and research on tourism resources in Tibet autonomous region. Beijing: Tsinghua University Press, 2008.

[3] State Council of the People's Republic of China, "Peaceful liberation and prosperous development of Tibet," Government of China, 2021. http://www.gov.cn/zhengce/202105/21/content_5609821.htm (accessed Nov. 19, 2021).

[4] Y. N. Fan, "Qinghai: Can the upgraded plastic ban control white pollution," China Tibet Network, 2020. http://www.tibet.cn/cn/ecology/202010/t20201013_6868817.h tml (accessed Nov. 19, 2021).

[5] Oxford Business Group, "How concerned should Asia Pacific be about the overdevelopment of tourism hotspots." https://oxfordbusinessgroup.com/analysis/greener-pasturesgovernments-asia-pacific-are-working-protect-topdestinations-overdevelopment-and (accessed Nov. 19, 2021).

[6] W. Chen, An exploration of ecotourism and sustainable development theory. Chengdu: Sichuan University Press, 2008.

[7] Environmental Protection Administration, Technical guidelines for the classification and management of nature reserves, Environmental Protection Standard of the People's Republic of China. Beijing: Environmental Protection Administration. 